\title{
Alternative Liability Regimes for Medical Injuries
}

\author{
by Patricia M. Danzon*
}

\section{Introduction}

In the U.S. physicians and other medical providers are subject to a negligence rule of liability. Under a negligence rule a patient who is injured as a result of medical care is entitled to compensation only if he or she can show that the injury was caused by the physician's failure to take due care. Given a finding of liability, compensation is determined by a civil jury. In recent years the frequency of malpractice claims has been increasing at 10 percent a year and claim severity (average amount per paid claim) has increased at twice the rate of general inflation. Malpractice insurance rates increased at 25 to 40 percent a year between 1985 and 1987 (Danzon, 1988). Coverage for high risk specialities and excess limits of coverage have reportedly been unavailable. Concern over this "crisis" has generated serious consideration of radical alternatives to the present negligence system, including nofault compensation schemes along the lines of those adopted in Sweden and New Zealand.

This "crisis" in the operation of the negligence system seems to belie the strong theoretical arguments in favour of a negligence rule of liability for medical care. Under a rule of first party liability (caveat emptor or no liability) if patients underestimate the risks associated with medical care physicians may take suboptimal care and perform too many risky procedures (Spence, 1977; Danzon, 1985). ${ }^{1}$ In principle a negligence rule of liability can correct these distortions, by internalising to physicians the costs of nonoptimal care. In theory, under a negligence rule in long run equilibrium there should be no malpractice claims and no demand for liability insurance since there should be no negligence: if the due care standard is efficiently defined, it is always cheaper to prevent injuries that would be deemed negligent than to take less care and insure against the resulting claims (Shavell, 1982). ${ }^{2}$

The empirical evidence contradicts the theoretical prediction that there should be no negligence, no claims and no demand for liability insurance. The frequency and severity of malpractice claims have been increasing steadily for the last two decades. Most physicians are unwilling to practice without liability insurance and over 40 percent carry at least

'University of Pennsylvania.

1 "Optimal" is defined as the level of care that patients would choose if fully informed. This inference of suboptimal care also depends on the physician's objective function. See Danzon (1989).

${ }^{2}$ A positive level of claims under an efficient negligence system might be explained if legal standards of care adapt to new technologies more rapidly than practice patterns of some physicians. This explanation is implausible for professional liability where due care is defined as the customary practice of the profession at the time of the allegedly wrongful act. 
$\$ 1$ million in coverage (Medical Economics, November 1983). The cost and/or lack of availability of malpractice insurance is allegedly interfering with the delivery of care, particularly in obstetrics, where recent surveys indicate that 12 percent of obstetricians have stopped doing obstetrics and 23 percent have stopped doing high risk procedures.

Critics of the tort system argue that its unpredictability precludes any positive deterrent value, and that it has degenerated into a system of no-fault compensation, at least for severely injured plaintiffs. If it is true that the tort system in practice serves primarily a compensation function, this is neither efficient nor equitable. Other private and public insurance programs deliver compensation with lower cost, less delay and greater certainty. The tort system delivers roughly $30-40$ cents on the liability insurance dollar as net compensation to injured plaintiffs. The remaining $60-70$ cents are absorbed in litigation costs and insurance overhead expenses. From the plaintiff's perspective the tort system thus provides insurance with a loading charge of between 150 and 200 percent. By contrast, private first party group health insurance delivers over 80 cents of the insurance dollar as net compensation to the patient. This implies a loading charge of under 25 percent. In addition, errors by the courts in setting the standard of due care can induce distortions in medical practice (defensive medicine).

The medical malpractice insurance crisis of the mid-70s prompted many states to modify traditional tort rules in an attempt to control the frequency and severity of claims. These measures include caps on awards for pain and suffering, collateral source offset and shorter statutes of limitations or repose. The insurance crisis of the mid- 80 s has generated interest in more radical alternatives to the negligence system. The American Medical Association (AMA) has proposed removing malpractice cases from the courts to a special administrative system. ${ }^{3}$ In 1987 the state of Virginia established a no-fault compensation fund for a very narrowly defined category of birth-related neurologic injuries. ${ }^{4}$ This follows enactment of special compensation funds for vaccine-related injuries at the federal level and by the states of California and North Carolina. Although these no-fault funds are limited in scope so far, they represent a radical departure from the principle of internalisation of injuries to the responsible parties, with financing through private liability insurance, that traditionally applies to all other medical, product-related, automobile and workplace injuries in the U.S. 5

This move from traditional tort-based negligence liability towards no-fault compensation schemes with broader tax based funding has been taken in response to political

${ }^{3}$ This proposal would clarify but basically retain a negligence standard of liability, and retain the current structure of damages but with collateral source offset and limits on awards for pain and suffering.

4 Virginia Birth-Related Neurological Injury Compensation Act, Code of Virginia Title 38.2 Chapter 50 . The fund is financed in part by a levy on all physicians and hospitals, with deficits to be recouped by an assessment on all life and health insurance companies operating in the state.

5 One partial exception is the federal Black Lung program for pneumoconiosis. This was intended to be financed largely by assessments on responsible coal mine operators, but in fact has received large federal subsidies. The limited no-fault automobile statutes that have been adopted in some states are based on first party liability but retain private insurance which can in principle be experience rated. The workers' compensation system is also sometimes called a no-fault system but it is more accurately described as a system of strict liability. Funding is through third party insurance that is strongly experience rated for most firms. 
pressures, without a full evaluation of the allocative effects and without a clear rationale for singling out certain categories of injury for special treatment. Rather, liability was curtailed in order to maintain the supply of essential services. In both cases, medical providers threatened to withdraw services in response to the increase in price or lack of availability of liability insurance. Similarly, problems with liability insurance have prompted the more limited tort reforms recently enacted for medical malpractice and product liability. This raises the interesting question of whether crisis in liability insurance markets are a reliable barometer of inefficiency in the underlying liability regime.

The purpose of this paper is to lay out a framework for evaluating the present negligence regime relative to possible alternatives for iatrogenic injuries. Both allocative and distributive effects are considered. If the criterion for choice of liability regime is allocative efficiency, the alternatives must be evaluated in terms of effects on at least three components: efficiency in resource allocation to injury prevention; allocation of risk between patients and physicians, assuming that full insurance is either not feasible (because of irreplaceable loss) or not optimal (because of moral hazard or overhead costs); and overhead costs of administering claims and insurance. If the criterion for choice is distributive effects, both short run and long run incidence of costs must be considered.

The existing literature on the economics of law lays the foundation for this comparison. Parts I - III of this paper apply this literature to the context of medical care, taking into account the realities of the judicial system and markets for medical care and liability insurance that are often ignored in theoretical models. Part IV lays out a framework for evaluating alternative liability regimes, in terms of welfare loss relative to the first best optimum. Alternatives considered included an imperfect negligence system, first party liability, strict liability financed through private liability insurance purchased by physicians, and a no-fault compensation fund financed by general revenues. ${ }^{6}$ The Appendix (available from the author) presents a model of physician behavior which shows that if the physician internalizes to some degree the utility of the patient, standard conclusions based on assumptions of non-cooperative behavior do not necessarily hold. The effects of alternative liability rules on patient welfare then become much harder to predict.

\section{Standard theory of alternative liability rules}

A useful starting point for comparison of alternative liability rules in a market setting is the Coase theorem (Coase, 1960). The rule of liability is irrelevant for both the allocation of resources and the distribution of income provided that (1) patients are fully informed about the risks of alternative treatments and can costlessly monitor the quality of care actually delivered and (2) all relevant transactions costs are negligibly low. In that case market contracts between patients and physicians would assure an optimal level of care and optimal compensation in the event of an adverse outcome. Physicians would agree to indemnify patients if third party insurance were cheaper than first party insurance.

More realistically, patients are less well informed than physicians about the risks of alternative treatments and the quality of care actually delivered may be unobservable to the patient until long after the treatment, and even then can sometimes only be inferred (1987).

${ }^{6}$ I do not consider alternative policy tools such as taxes and regulation. See, for example, Gravelle 
probabilistically. With asymmetric information a rule of no liability is likely to lead to nonoptimal levels of care, with precise effects depending on the physician's utility function and method of payment. If the physician is paid on a fee-for-service basis and if income or leisure enter his utility function, he is likely to perform too many risky procedures and take too little care per procedure. ${ }^{7}$ If the physician is paid on a capitation basis i. e. a fixed sum per patient per month, the incentive for too little care remains but not necessarily too many risky procedures. Similar conclusions apply if reimbursement is by salary. ${ }^{8}$

In principle incentives for suboptimal care per procedure can be corrected by imposing on the physician a rule of liability for negligent performance. To eliminate excessive number of risky procedures, the physician must also be held liable for performing "unnecessary" procedures. Necessary conditions for efficiency are (1) courts must define the level of due care and of "unnecessary" procedures in a way that conforms to what the patient would have chosen if fully informed; (2) courts must accurately perceive the level of care actually delivered and enforce the correct standard costlessly.

Efficiency of deterrence and compensation also requires that damages must be optimally set. The optimal level of compensatory damages is equal to what the patient would have been willing to pay for, given the load on the physician's liability insurance (Danzon, 1985 b). This would be equal to full compensation (the traditional tort standard) only under the unrealistic assumptions that (1) the injury does not affect the patient's marginal utility of income and (2) liability insurance is actuarially fair. Given optimal compensation, optimal deterrence may require an additional fine or "deterrence surcharge", equal to what the patient would have been willing to pay to reduce the risk of injury (Spence, 1977; Danzon, 1985 a). If the physician's negligence is responsible only for a marginal deterioration in the patient's condition (i. e. even with optimal care the patient would not have been restored to perfect health) then the physician should only be liable for the marginal damages. Under these assumptions physicians would never be negligent since it is cheaper to be nonnegligent than to take less than the optimal level of care and insure against the resulting liability. ${ }^{9}$

Optimal deterrence can in theory also be achieved by a rule of strict liability, whereby physicians are strictly liable for all iatrogenic (medically-caused) injuries. ${ }^{10}$ However, if efficient injury prevention also requires care on the part of patients, then strict liability achieves an efficient outcome only if combined with the defenses of contributory negligence

${ }^{7}$ See, for example, Spence, 1977; Danzon, 1985 b.

8 The outcome also depends on the sensitivity of demand to perceived quality of care. If patients perceive a physician's average quality but not the care in each instance, outcomes are likely to be worse under reimbursement through salary that is independent of number of patients seen than under a per patient capitation, assuming that number of patients enrolled is positively related to the perceived quality of care.

${ }^{9}$ This assumes that physicians are homogeneous in their costs of taking care or that the definition of negligence applied by the courts is sufficiently flexible to take account of heterogeneity in costs of care. If physicians are heterogeneous but courts define a single standard, say the median, then half of physicians might choose to be neligent and insure against the resulting claims. The fact that virtually all physicians carry insurance suggests that this is not the sole explanation of the demand for liability insurance.

${ }^{10}$ Further necessary conditions for a first best solution under strict liability are that liability insurance be actuarially fair and perfectly experience rated, which requires that the insurer can observe the physician's level of care, and that the physician suffers no irreplaceable loss from suit. 
and assumption of risk (Brown, 1975). A third alternative that is potentially efficient in theory is comparative negligence (Haddock and Curan, 1985).

While these three regimes can in principle all provide optimal incentives for care, they may not be equivalent in terms of allocation of risk and overhead costs. Specifically, if first party insurance is available to patients at lower cost (load) than the cost of liability insurance to physicians, then negligence or comparative negligence are likely to be superior to strict liability. In theory under either of these negligence-based regimes physicians would choose to be non-negligent so would not incur risk and would not purchase liability insurance. Patients would also be better off with optimal first party insurance than with compensation provided through the tort system since, as noted earlier, the optimal level of tort compensation is inversely related to the load on the physician's liability insurance. Since the load on liability insurance is higher than the load on first party insurance, patients have (optimally) less compensation under strict liability. The price of medical care is also higher by an amount sufficient to compensate physicians for their uninsured risk.

This conclusion, that patient welfare is likely to be lower under strict liability because of higher overhead and insurance costs, assumes that in the long run the incidence of these costs is on patients. The standard assumption in models comparing alternative liability rules (for example, Shavell, 1982; Danzon, 1985 b) is that the objective is to define a liability regime that maximizes the utility of the potential victim (patient), subject to a reservation level of utility for the injurer (physician). Thus by assumption there is no question of redistribution between patients and physicians or between different groups of physicians. In practice in the short run (which might be quite long) patients might be better off with a switch from negligence to strict liability, even if strict liability entails higher total costs, because the incidence of the higher costs may be on physicians who are immobile to other occupations and from high risk to low risk specialties except in the very long run.

\section{The negligence system in practice}

The actual operation of the malpractice system departs from the stylized model outlined above in a several fundamental ways.

Injuries and Claims Contrary to the prediction that the threat of liability should eliminate all negligence and hence eliminate claims alleging malpractice, all studies of iatrogenic injury indicate a nontrivial rate of negligent injury. The largest and most careful study so far of iatrogenic injuries (CMA, 1977) estimated an incidence of injuries due to negligence of one per 126 hospital admissions.

The frequency of claims per physician has been increasing at roughly 10 percent a year for the last decade. There is significant variation across specialties and regions of the country that cannot plausibly be attributed to differences in propensity to be negligent. Roughly $70 \%$ of obstetricians have been sued at least once in their career (ACOG, 1988). Nevertheless, averaging over all physicians, the rate of claims is probably still less than the rate of negligent injuries. ${ }^{11}$ Unfortunately with the data available it is impossible to determine

11 This conclusion is based on evidence from 1976 that at most one in ten injuries due to negligence resulted in a malpractice claim. Of these, just under half received some compensation through settlement or verdict. Danzon (1985 a). 
how far the increase in claims reflects (1) a higher rate of negligence; or (2) a higher rate of filing, given a negligent injury; or (3) an increase in the rate of filing of "nonmeritorious" claims. ${ }^{12}$

Since 1970 medical malpractice claim severity (the average payment per paid claim, including both jury verdicts and out-of-court settlements) has been growing in real terms. Over the decade 1975-84, severity increased at roughly twice the rate of increase of the general consumer price index (CPI). This difference cannot be fully explained by the more rapid increase in medical costs, since medical expense accounts for less than 25 percent of reported economic loss of malpractice plaintiffs (NAIC, 1978). Probably a larger fraction of the real increase in malpractice awards reflects higher payments for non-economic loss (pain and suffering). Data on jury verdicts in one jurisdiction (Cook County, Illinois) show that medical malpractice cases increased from 2.0 percent of all liability cases in $1959-1979$ to 4.6 percent in $1980-1984$. Over the same period, malpractice plaintiffs increased their share of total dollar indemnity fourfold, from 3.7 percent to 16.4 percent, and their share of total pain and suffering payments more than sevenfold, from 3.4 percent to 29.0 percent. ${ }^{13}$

Gross Costs of the Malpractice System The fact that claim frequency and severity are increasing does not necessarily proove that the system is inefficient, if previous levels of claims and compensation were suboptimal. One approach to evaluating whether the system yields positive net benefits is to compare gross costs and benefits. ${ }^{14}$ In practice the data required for such an evaluation are not available.

The most visible cost component is malpractice insurance premiums. Since 1980 malpractice insurance rates have increased between 10 and 30 percent a year, following a period of stable or falling premiums in the late 1970s. The real cost of coverage has increased more rapidly because higher limits of coverage are required to maintain a constant level of protection. The percentage of physicians carrying at least $\$ 1$ million in coverage increased from 21 percent in 1976 to 41 percent in 1983 (Medical Economics, November 1983). Malpractice premiums written were roughly $\$ 2.8$ billion in 1985 . Although this is less than $1 \%$ of the total health care spending of $\$ 425$ billion in that year, it constitutes on average $8 \%$ of expenditures on physician services, higher for high risk specialties such as obstetrics.

Part of this total expenditure on liability insurance is not a net social cost but a transfer to provide compensation. Estimates from various sources indicate that between 30 cents and 40 cents of the malpractice insurance dollar reaches the plaintiff as compensation. Litigation and insurance overhead absorb the remaining $60-70$ cents. ${ }^{15}$

12 This increase in claim frequency has occured despite no major explicit changes since the midseventies in the law governing medical malpractice. This is in contrast to product liability, where major doctrinal changes have occured from negligence to strict and even absolute liability.

${ }^{13}$ Based on data provided by George Priest, reported in Danzon, 1985 at 139. Estimates of payment for pain and suffering are imprecise because awards are rarely itemized so pain and suffering is computed as the difference between the award and the reported economic loss of the plaintiff. Estimates of trends in such payments may be upward biased if cases tried to jury represent an increasingly small fraction of the largest cases. However, it seems unlikely that such biases fully account for the estimated trends in compensation for pain and suffering.

${ }^{14}$ Of course even if it passes this test, it is still possible that structural reforms could yield higher net benefits. 
It is widely alleged that the direct costs of litigation are dwarfed by the indirect costs of "defensive medicine". Defensive medicine is defined here as medical practices that yield expected benefits to patients less than costs and that would not occur in the absence of the liability threat. This definition distinguishes defensive practices from the cost-effective changes in medical care that the tort system is intended to encourage ("prevention"). This definition of defensive medicine also distinguishes non-cost justified practices that are induced by the threat of liability from those that are a rational response to the moral hazard created by insurance for medical care. ${ }^{16}$

While the distinction between defensive and preventive measures is conceptually clear, making the distinction operational is much more difficult. Changes in medical practice - preventive or defensive - have certainly occured in response to the liability system. Hospitals have adopted extensive risk management programs. In a recent survey, 41 percent of physicians report ordering extra tests, 36 percent spend more time with patients, 57 keep more detailed records, and 45 percent refer more cases (Zuckerman, 1984). However, the total cost of these changes has not been reliably estimated. Reynolds and Rizzo (1987) have estimated the total costs of professional liability at $\$ 12$ billion, of which about $\$ 9$ billion is practice changes, but their methodology relies on very strong assumptions and does not distinguish cost-beneficial prevention from wasteful defensive practices.

Gross Benefits of the Malpractice System In principle, benefits are from two sources, deterrence of injury and compensation. There are simply no measures of the number of injuries that are prevented as a result of the care induced by the malpractice system, fundamentally because iatrogenic injuries, as opposed to malpractice, claims, are not observable through currently available data.

The value to patients of the compensation received through the tort system is equally hard to measure, but is probably less than its cost because of duplication, uncertainty, and non-optimal coverage. Current award levels pay at least twice (undiscounted) economic loss. Roughly 60 percent of this economic loss would be covered by other sources of public and private insurance, on average (Danzon, $1985 \mathrm{a}$ ), although duplication is less for certain groups and types of injury. Seventeen percent of the non-elderly U.S. population lacks either private or public health insurance. Even for those with basic health insurance, for specific types of loss (for example, birth defects, private nursing care and rehabilitation expense) tort awards are likely to be less duplicative of other public and private insurance coverages and therefore of higher value to patients. Aside from duplication, the insurance value of tort compensation is reduced by the fact that the amount is very uncertain ex ante, whereas the value of insurance lies in providing a stable stream of income.

15 Kakalik and Pace (1986) estimate total expenditures on litigation, including time costs of the litigants. These estimates do not include insurance overhead costs.

16 Insurance with a deductible and co-insurance rate, with traditional fee-for-service payment for medical care, reduces the point-of-service price of care to the patient. With such insurance, patients would want precautionary measures taken as long as marginal benefit exceeds marginal user cost which is less than marginal social cost. This excess should not be counted as defensive medicine, but operationally it is difficult to distinguish. 
The value of the pain and suffering component of compensation cannot be determined a priori, assuming that the marginal utility of income is state-dependent, but evidence from other private and public insurance programs suggests that it is not worth its cost. ${ }^{17}$

\section{What goes wrong?}

A basic lesson from the literature on market failure is that, even if the free market fails, government intervention is justified only if the government can do better. The same principle applies to the choice of producer liability or a social compensation scheme, in place of no liability. This section reviews the sources of allocative inefficiencies and distributive effects of alternative liability regimes.

The fundamental obstacle to the efficient functioning of alternative liability rules for purposes of deterrence and compensation is imperfect information. Asymmetry of information implies that a rule of no liability may not lead to a first best result, but simply changing the liability rule does not eliminate the asymmetry of information. Indeed it is possible that either negligence or strict liability with imperfect information may be no better or even inferior to no liability.

Deterrence Just as the care exercised by physicians is unobservable to patients ex ante, it is also unobservable ex post to patients, to courts and to liability insurers. This asymmetry of information undermines the efficiency of a negligence regime, just as it undermines the efficiency of first party liability. Imperfect ex post information on the part of patients leads to the filing of non-meritorious claims. Imperfect ex post information on the part of courts induces inefficient behavior through several channels.

As Craswell and Calfee (1986) show, variance in the determination of the due care standard can induce either suboptimal and excessive precautions, even if the standard is correct on average. Further, since courts cannot observe the true standard of care, they may use observable proxies. For example, liability may be determined on the basis of observable inputs - diagnostic tests performed or adherence to a predefined code of standards - rather than whether the physician actually exercised optimal judgement and care for the specific patient. If liability is determined on the basis of observable proxies rather than true care, physicians have incentives to invest in these proxies and possibly substitute them for true care in order to reduce the probability of being found liable. This is one form of defensive medicine. Incentives to adopt this form of defensive practice depends on the production function of medical care (substitution possibilities between defensive and true preventive measures), the information available to the patient and the form of reimbursement. See Appendix and Danzon (1985b).

Imperfect information on the part of courts and plaintiffs creates incentives for physicians to purchase liability insurance (Danzon, 1985b). Both Type I errors (failure to file a

17 The optimal level of compensation for non-economic loss depends of the parameters of the utility function (Cook and Graham, 1976). The preferences revealed in private insurance purchases and other social insurance programs suggest that compensation for pain and suffering is not worth its cost, possibly because of moral hazard when the magnitude of loss is unobservable, and adverse selection. Moral hazard is not eliminated by providing insurance through the tort system. Adverse selection may be mitigated, because the coverage is compulsory. But if liability insurers cannot observe which physicians treat high risk patients and liability insurance is not compulsory, the using the tort system to make tort coverage for patients compulsory does not eliminate the problems caused by adverse selection. 
claim or failure to find negligence on all valid claims) makes it cheaper to be negligent and purchase insurance against partial claims than to always be non-negligent. Type II errors (finding liability where in fact due care was taken) exposes the physician to exogenous risk and creates a demand for liability insurance. Since the physician's true care is not observable to courts or to liability insurers, perfect experience rating is not feasible. The optimal contract may then involve both moral hazard and uninsured risk to physicians (Shavell, 1982).

A further consequence of imperfect information on the part of courts is an incentive for both parties to incur litigation expense. If the physician's care and the correct due care standard were readily observable, the outcome at verdict would be known and the litigants would presumably settle immediately. When both actual care and due care are unknown, both parties have an incentive to incur expense in an effort to influence the court's perception of the truth. This generates a demand for insurance against litigation expense. When the liability insurer also provides the legal defense, the use of co-payments to control the physician's incentives becomes less attractive. If the liability insurer faces only part of the loss, the incentives for legal defense are suboptimal. Thus using co-payments creates a trade-off between loss control through injury prevention and through legal defense (Danzon, 1985b).

Compensation Imperfect information undermines the efficient delivery of compensation through the tort system, just as in private insurance markets. One problem is that the true damages suffered by the plaintiff are unobserved. The tort system is even more exposed to moral hazard on the part of claimants (filing exaggerated or fraudulent claims) than first party private and public insurance would be. The tort system is unique in having no predermined indemnity schedule that defines the amount to be paid before the occurrence of an injury. Rather, compensation is determined after the occurrence of the injury by persons - judge or jury - who bear an infinitesimal fraction of the cost. The tendency in many settings for society to be willing to spend much more to compensate or prevent injury to an identified victim ex post than ex ante on statistical lives is well known. It is one plausible explanation of why jury awards are higher than compensation paid in any other private or social insurance program and, for a given injury, awards are higher when the defendant is a physician or corporation than against individual defendants (Chin and Peterson, 1985).

Partly because the plaintiff's true loss is unobservable to juries, awards are erratic and hence unpredictable. Unpredictability of awards implies that for a risk averse patient, the utility value of tort compensation is less than its cost to physicians. The utility value of tort compensation is further reduced to the extent it simply duplicates other private or public coverages. This duplication results from high costs to other private and public insurers of monitoring tort claims and filing subrogation claims.

In cases of injuries with multiple contributing factors - the underlying disease or genetic predisposition vs. the physician's care - imperfect information undermines the ability of courts to determine the marginal contribution of each factor and hence to assess each liable defendant only for his or her marginal damage. If courts resolve this uncertainty in a systematically biased way, assessing all damages against a single contributing party, this operates like a tax on that party or activity and can lead to withdrawal of goods and services that optimally should not be withdrawn.

Non-diversifiable Risk Inability of courts to observe the defendant's true care and the plaintiff's true damages creates the potential for unanticipated changes in liability rules or 
standards of damages. Unpredictability of future change in legal standards create a risk to liability insurers that is not diversifiable through pooling large numbers since it applies equally to all insureds in the insurance pool. This socio-legal risk tends to raise the equilibrium price of liability insurance and create incentives for self-insurance and mutualisation (Danzon, 1984; Doherty and Dionne, 1988). It also contributes to volatility in insurers' losses and capacity, and hence to volatility in prices and availability of coverage (Winter, 1988; Cummins and Danzon, 1988). The incidence of this volatility - short run deviations from trend in the cost and availability of liability insurance - is likely to be largely on physicians who cannot increase medical fees in the short run. Socio-legal risk that stems from imperfect information in the tort system thus contributes to the periodic "crises" in liability insurance markets and the demand for reform or replacement of the tort system.

Long Run Incidence of Costs of the Negligence System Imperfect information affects not only the total social costs of the tort system but also the long run incidence of these costs. If patients accurately perceived tort benefits and valued them at cost, the incidence of the costs (and benefits) of the malpractice system would be fully on patients and there would be no distortions in the delivery of medical services. ${ }^{18}$

The long run incidence of costs of the liability system will be on physicians to the extent it imposes costs on physicians that exceed the benefits perceived by patients. All of the following factors could contribute to this result: 1 . patients may underestimate the reduction in injury risk induced by increased care by physicians; 2 . physicians may incur uninsured time and worry costs that do not have positive deterrence benefits; 3 . litigation and insurance overhead costs; 4 . patients may underestimate tort compensation or value it at less than cost because it is uncertain, partially duplicative of coverage from other private and public insurance, and possibly non-optimal in compensating for non-pecuniary loss. Also, to the extent changes in liability rules apply retroactively, costs in competitive markets will be borne by producers.

The admittedly rough empirical evidence is certainly consistent with the hypothesis that the short run incidence of costs of expanding liability is partly on physicians, particularly after a sharp premium increase. The insurance "crises" of the mid 1970s and mid 1980s have led to strong pressure by the medical profession for reform of the malpractice system. But the short run incidence is partly determined by rigidities in the adjustment of reimbursement levels by third party payers, so is an imperfect indicator of shifts in the demand for medical services.

Further, although incidence of costs on physicians is consistent with patients not valuing the tort system at cost, this evidence does not necessarily imply that the tort system is inefficient. Even if the system operated perfectly and costlessly, to the extent patients misperceive either the deterrence or the compensation value of the tort system, just as they misperceive the risks of medical care that justify the system in the first place, then the incidence of expanding liability will be partly on physicians. Physicians would oppose the system even though on pure efficiency grounds it may be cost-effective.

18 The demand for medical care would shift by at least as much as the increase in cost, leading to an increase in price and an increase or no change in quantity. 


\subsection{First party liability}

It is well known that under first party liability with uninformed patients and systematic underestimate of risk, physicians have suboptimal incentives for care and patients purchase suboptimal insurance (for example, Spence, 1977).

Less attention has been given in the law and economics literature to imperfect information on the seller side of private insurance markets, which can lead to moral hazard and adverse selection and hence to levels of care and insurance coverage that are not first best. Since group-based first party health and disability insurance is not individually experience rated, individuals have suboptimal incentives for care, including suboptimal incentives to avoid high risk activities and products. Thus even if consumers are fully informed about product risks, producers have suboptimal incentives for care and the level of risky activities is too high.

Adverse selection in first party insurance markets appears to contribute to nonoptimal insurance coverage for long term medical expenses and wage loss. Employment-based group plans provide a solution to the adverse selection problem as long as the individual remains employable. The individual who is sufficiently disabled to lose his job and lose access to group insurance can purchase non-group private health insurance but faces loading charges of 100 percent or more (loss ratios of .5 or less) and possibly exclusion of preexisting conditions. The risk of becoming high risk can be insured against by purchasing a non-group policy that is guaranteed renewable at class rates, but with very high loads. There is essentially no private insurance against permanent partial wage loss or against the risk of giving birth to a child suffering from a major birth defect. The private insurance market for long term care is growing but still very small and high cost, particularly for nongroup coverage.

Thus private first party insurance markets provide poor protection against the risk of becoming high risk. To the extent the problem is adverse selection, government intervention to make coverage compulsory can be Pareto improving (Pauly, 1976; Wilson, 1977). Since a strict third party liability rule effectively makes insurance compulsory, by tying the right to compensation to the product or service, in principle there might be a welfare gain in terms of insurance for potential victims, from switching from first party to strict liability. The presumption that producer liability provides a more efficient vehicle for risk spreading underlies several court rulings assigning strict liability for product-related injuries. But this conclusion ignores the problems created by imperfect information in operating a liability system and liability insurance. ${ }^{19}$ Ultimately the relative efficiency of first and third party liability rules for purposes of risk spreading is an empirical question.

\subsection{Strict liability financed by private liability insurance}

Strict liability applied to all iatrogenic injuries and financed through private liability insurance could in practice simply exacerbate the distortions present under a negligence rule. Iatrogenicity may be just as unobservable as negligence. A broad definition of iatrogenic disease includes negligent and non-negligent injuries, anticipated and inevitable complications as well as unanticipated and inadvertent complications of treatment, and

19 Priest (1987) and Cummins and Danzon (1988) discuss adverse selection in liability insurance markets. 
errors of omission as well as commission. But the current state of knowledge is very imperfect about the relative role of medical care vs. other factors in "causing" many adverse medical outcomes. Because the ability to prevent disease is highly technology dependent there is a severe risk of retroactive application of new standards. The question of what quality of care the patient could reasonably expect, given the terms of his health insurance contract, is also ambiguous and a potential subject of litigation under a system that attempts to compensate for iatrogenic injury but not for adverse outcomes that are the "natural" consequence of the patient's presenting condition. If liability insurance premiums are experience-rated in order to preserve incentives for care, apportioning damages among multiple contributing parties will require finding degrees of fault.

If it is as costly to determine iatrogenicity as it is to determine negligence then eliminating the fault requirement and moving to strict liability will not generate significant savings per case in litigation expense. Number of cases filed could increase at least fivefold. ${ }^{20}$ Thus, even if the switch to no-fault were accompanied by a limit on compensable damages to pecuniary loss that is not compensable from other sources, malpractice premiums could increase significantly, to levels equal to or greater than physician net incomes. Even small percentage fluctuations in premiums would then imply much larger fluctuations in physicians' net incomes that would lead to intense pressure against experience rating and in favor of broader based funding. Consistent with this, the Virginia no-fault plan for neurologically impaired infants relies largely on a broad-based tax on medical providers and other insurers. ${ }^{21}$

Even if fault-finding is eliminated, incentives for defensive practice could increase if physicians' total uninsured costs increase. In particular, with imperfect information on iatrogenicity the expected uninsured time costs for treating very sick patients who have low probability of complete recovery or high risk cases would probably increase. Physicians' incentives to practice defensively, including avoiding high risk cases could consequently increase.

Offsetting these costs are any benefits to patients in terms of insurance for losses that are not covered by other private and public coverages. The net value of such additional compensation depends critically on the reason for the gaps in private insurance. Compulsory coverage through any social insurance mechanism, including tort, would not be welfare improving for coverage that is optimally not provided because of moral hazard. On the other hand, to the extent the gaps in private insurance result from adverse selection or myopia, insurance provided through the liability system could be Pareto improving, depending on the terms of the coverage. Even in this case, because insurance provided through the liability system could not cover those losses that are not caused by a third party (for

20 This is a conservative estimate, based on the evidence from the CMA (1977) study that $17 \%$ of adverse outcomes as detected from the hospital records would probably have resulted in a verdict for the plaintiff under the prevailing negligence regime. It ignores the fact that only an estimated one in ten of negligently injured victims filed a claim (Danzon, 1985) and the potential for claims where the patient perceives that he has been injured even though by the criteria used in the CMA study the adverse outcome might not have been deemed compensable.

21 A likely response to this scenario would be that physicians would be more willing to enter into agreements with hospitals, whereby the hospital would pay for the physician's liability insurance in return for greater control over the physician's practice. 
example, cancers of genetic origin) gaps in coverage would remain unless the system becomes totally unprincipled, in which case it becomes an arbitrary tax on producers.

\subsection{No-fault compensation financed by general revenues}

Under this option the criterion for compensation would be the same as under strict liability of physicians, i.e. all iatrogenic injuries. However, the compensation would be financed through general taxes rather than through liability insurance purchased by individual physicians.

Uninsured risk to physicians would certainly be reduced. This would reduce incentives for wasteful defensive practices but also reduce incentives for beneficial preventive practices. The net effect on efficiency in the provision of medical care is therefore uncertain.

There might be some savings in insurance overhead if the public mechanism operated at lower costs than private liability insurance. However, there would also be an excess burden from raising the general tax revenues.

\section{Estimating the welfare loss from alternative liability rules}

Welfare loss is one criterion for evaluating alternative liability rules. Welfare loss has three possible components: non-optimal resource allocation to medical care; non-optimal insurance; and overhead costs. As a benchmark against which to measure the loss, I use the optimum that would be achievable with symmetry of information between patient and physician about the risks and benefits of alternative medical strategies and about the quality of care actually delivered. ${ }^{22}$ This is called full information.

The welfare loss from alternative liability rules is illustrated in Figures 1 -3. In Figure 1 let $D_{o}$ and $C_{o}\left(h_{o}, t_{0}\right)$ denote the demand and marginal cost functions for medical treatment (episodes of care) if patients are fully informed. Marginal cost is a function of the physician's true preventive effort, $h$, and of purely defensive inputs, $t$, that reduce the risk to the physician of successful suit, given an injury, but do not reduce the probability of injury. Defensive inputs could include extra tests or extra visits. With full information $t_{o}=0$. $P_{o}$ and $Q_{o}$ are the equilibrium price and optimal quantity of medical treatment that would be achieved under no liability, if patients were fully informed, or under negligence, if courts were fully informed.

\subsection{First party liability}

Under a rule of no liability with uninformed patients, physicians have incentives to provide suboptimal information to patients about the risks of treatment and to take suboptimal care per procedure. Let subscript " $u$ " denote this case. Assuming that patients underestimate the risks of treatment, the demand for treatments is too high $\left(D_{u}>D_{o}\right)$, prevention effort per treatment is too low $\left(h_{u}<h_{o}\right)$ and the supply price of medical services is too low $\left(C_{u}<C_{o}\right)$. Patients use more medical services than they would if risks were known $\left(Q_{u}>\right.$

\footnotetext{
${ }^{22}$ This begs the question of whether alternative liability rules influence the incentives of physicians to invest in information. This would not be a valid assumption for product-related injuries, where manufacturer liability for design and warning "defects" is likely to influence the investment in information about product risks.
} 
$Q_{o}$ ). The dotted line $D_{u}^{T}$ denotes the true demand i. e., the value that consumers would place on medical services if they accurately perceived the risks. $D_{u}^{T}$ lies below $D_{o}$ because the physicians' preventive effort is lower $\left(h_{u}<h_{o}\right)$. By the definition of $h_{o}$ as an optimum, the downward vertical shift of the demand function (which reflects patients' true willingness to pay for additional prevention) exceeds the downward vertical shift of the cost function: $V_{o}\left(Q_{o}\right)-V_{u}\left(Q_{o}\right)>C_{o}\left(Q_{o}\right)-C_{u}\left(Q_{o}\right)$, where $V($. $)$ denotes the marginal value of care to the patient.

The welfare loss under first party liability when patients underestimate risk is given by:

$$
W L_{u}=\left(C_{u}-V_{u}\right) Q_{u}+1 / 2\left(Q_{u}-Q_{o}\right)\left(V_{u}-V_{u}^{T}\right)
$$

Let $V_{u}=w_{u} C_{u}, V_{u}=\left(1+s_{u}\right) V_{u}^{T}$ and $V_{u}^{T}=g_{u} C_{u}$. Thus $w_{u}<1$ reflects the ratio of the value of care to the patient and the cost to the physician; $w_{u}$ is lower, the greater the excess of patients' willingness to pay for more prevention over the cost. The welfare loss under first party liability can be written : ${ }^{23}$

$$
\begin{aligned}
W L_{u} & =\left(1-w_{u}\right) C_{u} Q_{u}+1 / 2 E s_{u}^{2} V_{u}^{T} Q_{u} \\
& =\left[\left(1-w_{u}\right)+1 / 2 E s_{u}^{2} g_{u}\right] C_{u} Q_{u}
\end{aligned}
$$

where $E$ is the price elasticity of demand for medical care. The first term in equation 1' represents the welfare loss due to suboptimal care per procedure. This loss will be large if physicians are very poor agents for imperfectly informed consumers. The loss will also be large if informed consumers would place a high value on risk reduction, possibly because of incomplete first party insurance and irreplaceable losses if injured.

The second term reflects the welfare loss from excessive use of medical care, given the risks. This loss tends to be large if physicians fail to warn patients of risks in the absence of liability for lack of informed consent ; if the cost of care drops significantly because of reduction in precautions by physicians; and if the demand for care is highly price elastic. Thus the welfare loss under no liability will be relatively small if physicians are good agents for their patients, in taking appropriate care per procedure and warning of risks, and if the demand for care is inelastic.

Figure 1 can also be interpreted as showing the potential welfare gain from going from a regime of no liability with uninformed patients to a perfect negligence system.

\subsection{Noisy negligence system}

Figure 2 shows the welfare loss from a negligence system that operates with imperfect information. The imposition of liability leads physicians to take more care than under no liability $\left(h_{n}>h_{u}\right)$ and possibly more care than under full information $\left(h_{n}>-<h_{o}\right)$. If courts use observable inputs (such as tests) as proxies for unobservable true care (physician time

$$
\begin{aligned}
& \quad{ }^{23} \text { From the definition of elasticity of demand } E=-\frac{Q_{u}-Q_{o}}{Q_{u}} \frac{V_{u}^{T}}{V_{u}^{T}-V_{u}} \text {, thus } Q_{u}-Q_{o}=E \frac{V_{u}-V_{u}^{T}}{V_{u}^{T}} Q_{u} \\
& =E s_{u} Q_{u} \text {. }
\end{aligned}
$$

The measures of welfare loss in equations (1) - (3) are exact only if the marginal utility of income is constant. Hausman (1981) shows that measures of welfare loss derived from the Marshallian demand curve may be quite inexact for a good which accounts for a large share of consumer budgets. Medical care accounts for 11 percent of GNP. However estimated price elasticities of demand for medical care are quite low. 
and effort) then the physician may adopt non-optimal defensive practices $\left(t_{n}>0\right)$. The physician may also purchase liability insurance. Thus the shift in the cost function reflects physicians' optimizing decisions with respect to preventive and defensive changes in practice patterns, purchase of liability insurance and any perceived increase in the opportunity cost of practicing medicine due to uninsured risk. The cost function under a negligence regime may be higher than under perfect information although this is not necessarily the case $\left(C_{n}>-<C_{o}\right)$.

The shift in the demand function $\left(D_{n}-D_{u}\right)$ depends on whether the introduction of a negligence system changes patients' perceptions of risks of medical care and the value that they place on tort compensation. Figure 2 is drawn with a net increase in demand. The vertical shift in the demand function is less than the increase in the cost function under the assumptions that (1) the imposition of negligence liability has little or no effect on patients' perception of risk of injury, and (2) tort compensation is valued by patients at less than cost of liability insurance to physicians. This assumption seems plausible for the reasons discussed earlier: uncertainty reduces the utility value of tort compensation to risk averse plaintiffs; duplication with other private and public insurance; high effective load, due to legal and time costs. Under these assumptions, the vertical shift in the demand function is less than the shift in the cost function, even with zero defensive practices and uninsured risk to physicians.

Assuming that liability induces some increase in prevention, the true value of medical care to patients is higher under an imperfect negligence regime than a no liability regime with imperfect information $\left(D_{n}^{T}>D_{u}^{T}\right)$. The vertical shift $D_{n}^{T}-D_{u}^{T}$ reflects the sum of the utility gain from risk reduction and net increase in compensation. These benefits could be greater or less than the increase in cost, relative to no liability.

The welfare loss from an imperfect negligence system, measured relative to the full information optimum, is :

$$
W L_{n}=\left(C_{n}-V_{n}\right) Q_{n}+1 / 2\left(Q_{n}-Q_{o}\right)\left(V_{n}-V_{n}^{T}\right)
$$

Let $V_{n}=w_{n} C_{n}, V_{n}=\left(1+s_{n}\right) V_{n}^{T}$ and $V_{n}^{T}=g_{n} C_{n}$. Then

$$
\begin{aligned}
W L_{n} & =\left(1-w_{n}\right) C_{n} Q_{n}+1 / 2 E s_{n}^{2} V Q_{n} Q_{n} \\
& =\left[\left(1-w_{n}\right)+1 / 2 E s_{n}^{2} g_{n}\right] C_{n} Q_{n}
\end{aligned}
$$

The first term reflects the costs of defensive medicine; the increase in opportunity cost of physicians due to uninsured risk; and the difference between the cost of liability insurance to the physician and the value of tort compensation to patients. The second term reflects the costs of excessive utilization. It could be zero if the shift to a negligence regime induces a large increase in costs of defensive practices etc. and hence a large increase in the price of medical care but little shift in demand. The welfare loss will be greater if the definition of negligence is confined to negligent performance and does not include liability for performing "unnecessary" procedures or failure to obtain informed consent ${ }^{24}$

\subsection{Strict liability}

Strict liability on physicians, financed through private liability insurance purchased by physicians has effects similar to a noisy negligence system but possibly of greater magnitude.

${ }^{24}$ In practice physicians are liable for failure to obtain informed consent only if there is an injury. 
The cost curve shifts up further, assuming an increase in liability insurance costs (any savings in litigation costs per case are dominated by the increase in number of cases) and uninsured time costs that dominate any savings in defensive inputs (which could be negative). The actual demand curve may shift up, depending on patients' perception of changes in risks of medical care and the value they place on tort compensation. The true demand curve also shifts up depending on the true valuation of any reduction in risk and increase in compensation.

Relative to a noisy negligence system, strict liability may result in higher welfare cost from defensive practices. Welfare cost from excessive use of risky procedures will be reduced; but this could go too far, with suboptimal utilization if increase in cost of care is large and demand is relatively elastic.

\subsection{No-fault compensation}

Figure 3 shows the welfare loss from a regime with no-fault compensation for iatrogenic injuries, funded through general revenues. As drawn, the figure assumes that physicians' level of care corresponds to the care under no liability $\left(h_{c}=h_{u}\right.$ and $\left.t_{c}=t_{u}=0\right)$. However, there could be an increase in care $\left(h_{c}>h_{u}\right)$ and upward shift of the cost function if non-tort quality control mechanisms are strengthened. Similarly, costs could rise if physicians incur uninsured time costs under the no-fault regime and therefore engage in defensive practices. Indeed these uninsured costs could be higher than under negligence, if shifting to a rule of compensation for all iatrogenic injuries greatly increases the number of claims filed, but does not reduce uninsured costs per claim because of the time costs of testifying on iatrogenicity.

The demand curve shifts outward, under the assumption that patients place some value on the increased compensation but their perception of the risks of medical care is unchanged.

With these assumptions the welfare loss with a system of no-fault compensation financed by general revenues is given by:

$$
W L_{c}=\left(C_{c}-V_{c}\right) Q_{c}+1 / 2\left(Q_{c}-Q_{o}\right)\left(V_{c}-V_{c}^{T}\right)
$$

Let $V_{c}=w_{c} C_{c}, V_{c}=\left(1+s_{c}\right) V_{c}^{T}$ and $V_{c}^{T}=g C_{c}$

Equation (3) can then be written:

$$
\begin{aligned}
W L_{c} & =\left(1-w_{c}\right) C_{c} Q_{c}+1 / 2 E s_{c}^{2} V_{c}^{T} Q_{c} \\
& =\left(1-w_{c}\right) C_{c} Q_{c}+1 / 2 E s_{c}^{2} g C_{c} Q_{c} \\
& =\left[\left(1-w_{c}\right)+1 / 2 E s_{c}^{2} g\right] C_{c} Q_{c}
\end{aligned}
$$

This measure of the welfare loss in the market for medical care excludes the deadweight costs of raising the taxes required to fund the compensation plan.

Comparing the no-fault compensation plan to no liability, the welfare loss from suboptimal care per procedure is the same or greater under no-fault, if some incentives for defensive practices remain. The welfare loss from excessive number of risky procedures is unambiguously greater under no-fault, if consumers place some value on the compensation for risk but the cost is not internalized to the medical sector. Thus no-fault dominates no liability only if these costs, plus the deadweight costs from raising taxes to fund the program, are outweighed by the value of the increased compensation, net of the costs of 
administering the no-fault scheme. This suggests the obvious conclusion, that welfare costs of a no-fault plan could be minimized if it is funded by a tax on those risky medical activities that generate the injuries. ${ }^{25}$

\section{Conclusion}

In general, factors which make provider liability relatively more attractive than no liability are low costs to courts and insurers of observing fault and iatrogenicity; physicians are very imperfect agents for their patients in the absence of liability; an elastic demand for care; imperfect first party insurance and high patient valuation of risk reduction and compensation.

This suggests that the optimal liability regime may be different for different types of injury - assuming type of injury is readily observable so this does not become an additional source of litigation. For example, it is possible that a no-fault compensation plan such as the Virginia plan dominates a noisy negligence system for neurological birth defects but not for routine surgical injuries. In the case of birth defects, the variance in court determinations of fault may be atypically high because of limited understanding of the causes of birth defects; value of compensation is high because of the large, long term expenses that are not covered by other private or public insurance in the U.S.; and relatively low elasticity of demand and hence small deadweight loss from failure to internalize costs to the risky activity. Nevertheless, the value of deterrence is presumably also higher for birth defects than for more rountine injuries, because of the irreplaceable nature of the loss. If the negligence system has any positive deterrent effects that are eliminated by the move to no-fault, it is conceivable that this dominates the net calculation and the optimal choice of liability regime remains ambiguous.

Since several of the key parameters required for the overall evaluation of alternative liability rules are in principle unobservable. An empirical observation, that physicians bear part of the cost of an increase in provider liability, is necessary but not sufficient evidence that such a shift is efficient. One approach to quantifying the trade-offs between alternative liability rules is to use simulation modelling, with sensitivity analysis on the unobservable parameters together with empirically based estimates of observables. This is the subject of ongoing research which we hope to report on in the near future.

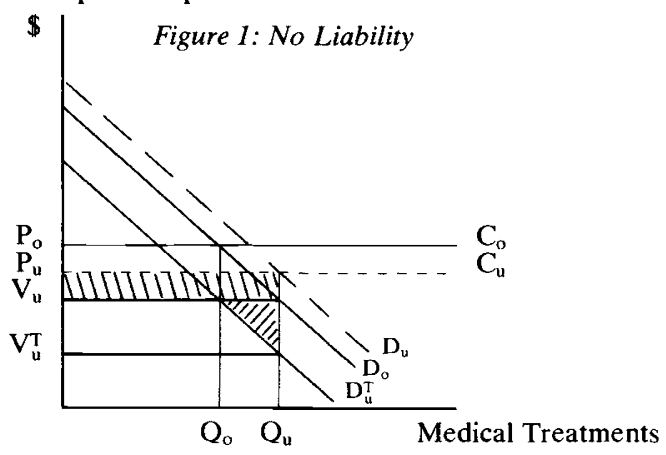

25 This would achieve general deterrence (optimal level of the activity) but not specific deterrence (optimal incentives for each provider) which requires individually experience rated liability insurance. 


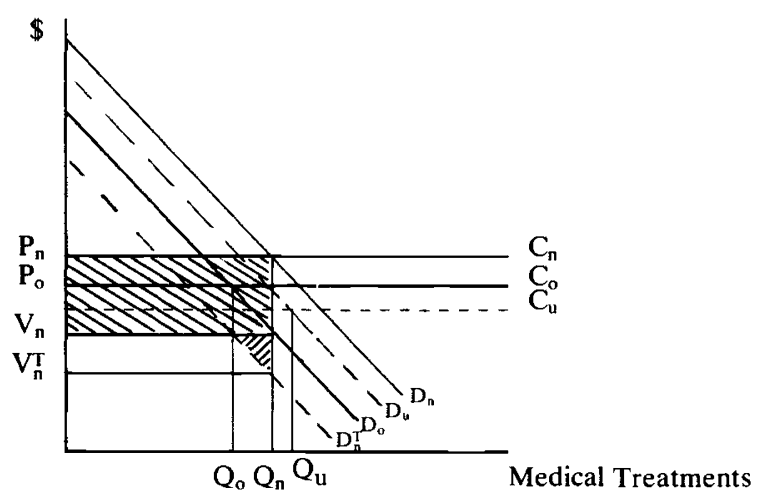

Figure 3: No-Fault Compensation

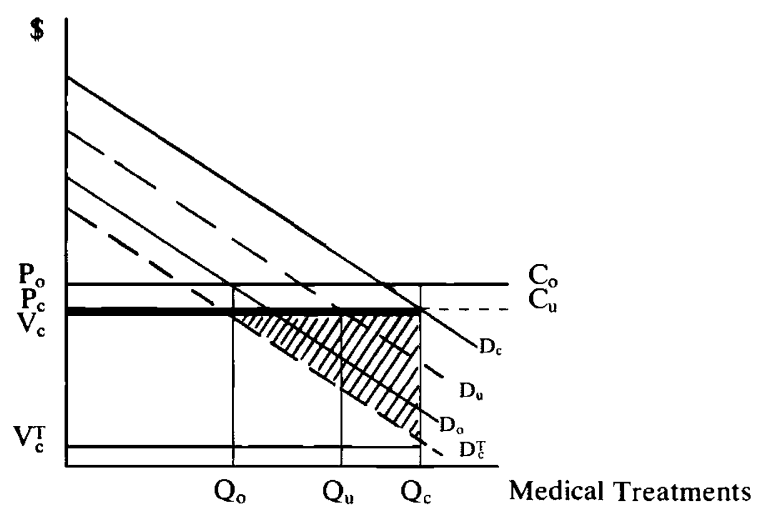

\section{REFERENCES}

American College of Obstetricians and Gynecologists [1988], Professional Liability and its Effects. Washington D.C.

BROWN, J. P. [1973], “Towards an Economic Theory of Liability”. J. Legal Studies 2:323.

California Medical Association (CMA) [1977], Medical Insurance Feasibility Study. San Francisco: Sutter Publications.

CHIN, A. and PETERSON, M. A. [1985], "Deep Pockets, Empty Pockets: Who Wins in Cook County Jury Trials". R-3249-ICJ. Santa Monica: The Rand Corporation. 
COASE, R. [1963], "The Problem of Social Cost". J. Law and Economics 3:1.

COOK, P.J. and GRAHAM, D.A. [1977], "The Demand for Insurance and Protection: The Case of Irreplaceable Commodities". Quarterly J. of Economics 91:143.

CRASWELL, R. and CALFEE, J.E. [1986], "Deterrence and Uncertain Legal Standards”. J. of Law, Econ, and Organization 2:279.

CUMMINS, J.D. and DANZON, P.M. [1988], "Capital Flows and Underwriting Cycles in Liability Insurance". Working Paper. The Wharton School.

DANZON, P.M. [1984], "Tort Reform and the Role of Goverment in Private Insurance Markets". $J$. Legal Studies 13 (3):517.

DANZON, P.M. [1985 a], Medical Malpractice: Theory, Evidence and Public Policy. Cambridge: Harvard University Press.

DANZON, P.M. [1985b], "Liability and Liability Insurance for Medical Malpractice". J. of Health Economics 4:309.

DANZON, P. M. [1985c], "Florida Malpractice Awards for Pain and Suffering". In Medical Malpractice Policy Guidebook, edited by H. Manne, Jacksonville, Florida: Florida Medical Association.

DANZON, P.M. [1986], "New Evidence on the Frequency and Severity of Medical Malpractice Claims", R-3410-ICJ. Santa Monica: The Rand Corporation.

DANZON, P. M. [1988], "Medical Malpractice Liability". In Liability: Perspectives and Policy, edited by Litan and Winston. Washington D.C. The Brookings Institution.

DANZON, P.M. [1989], "An Evaluation of Alternative Liability Regimes for Medical Injuries". Mimeo. University of Pennsylvania.

DOHERTY, N. A. and DIONNE, G. [1988], "Risk Pooling, Contract Structure and Organizational Form of Insurance Firms". Mimeo. University of Pennsylvania.

GRAVELLE, H.S.E. [1987], “Accidents, Taxes, Liability Rules and Insurance”. Geneva Papers on Risk and Insurance 12(13): 115

HADDOCK, D. and CURRAN, C. [1985], "An Economic Theory of Comparative Negligence”, J. of Legal Studies 14:49.

KAKALIK, J.S. and PACE, N. M. [1986], "Costs and Compensation Paid in Tort Litigation". R-3391ICJ. Santa Monica: The Rand Corporation.

National Association of Insurance Commissioners. [1980], Malpractice Claims. 2(2). Brookfield, Wis.

PAULY, M. [1974], "Overinsurance and Public Provision of Insurance". Quarterly J. of Economics $88: 44$.

PRIEST, G. [1987], "The Current Insurance Crisis and Modern Tort Law". The Yale Law Jornal 96:1426.

REYNOLDS, R.A., RIZZO, J.A. and GONZALEZ, M.L. [1987], "The Cost of Professional Liability". J. of American Medical Association May 22/29, 1987.

SHAVELL, S. [1982], "On Liability and Insurance” Bell J. of Economics 13:120.

SPENCE, M. [1977], "Consumer Misperceptions, Product Failure and Product Liability". Review of Economic Studies 64:561.

WILSON, C. [1977], “A Model of Insurance Markets with Incomplete Information“. J. Economic Theory 16:167.

WINTER, R. A. [1988], "The Liability Crisis and the Dynamics of Competitive Insurance Markets". Yale Journal of Regulation 5:455.

ZUCKERMANN, S. [1982], "Medical Malpractice: Claims, Legal Costs and the Practice of Defensive Medicine". Health Affairs 3:128. 